Journal of Electronics and Informatics (2020)

Vol.02/ No. 01

Pages: $18-29$

http://www.irojournals.com/iroei/

DOI: https://doi.org/10.36548/jei.2020.1.003

\title{
Cost Effective Energy-Saving System in Parking Spots
}

\author{
Dr. Akey Sungheetha \\ Data Science SIG member, \\ Computer Science and Engineering, \\ School of Electrical Engineering and Computing, \\ Adama Science and Technology University, \\ Adama, Nazret, Ethiopia. \\ Dr. Rajesh Sharma R \\ Image Processing SIG member, \\ Computer Science and Engineering, \\ School of Electrical Engineering and Computing, \\ Adama Science and Technology University, \\ Adama, Nazret, Ethiopia.
}

\begin{abstract}
Vehicles are becoming an essential product in everyone's life. Keeping a vehicle in a safe place will improve the life of its engine and other electrical systems. Hence, parking place occupies a major portion while constructing a house, apartment and shopping malls. The lighting system in such places are utilizing more energy and it leads to unnecessary expense on electricity bills. The proposed microcontroller based energy saving system is developed to minimize the utilization of light energy in parking spaces in an efficient manner. The results of the proposed system is compared with the general operation for identifying its efficiency. The proposed method saves the energy up to $46.35 \%$ than the existing lighting system.
\end{abstract}

Keywords: Parking System, Electricity Utilization, Energy Saving, Microcontroller, Light System

\section{Introduction}

Light is one of the basic source given by the nature to all living things for leading their life. After the invention of electric lamps and bulbs, the life of humans have changed a lot. Natural light does not cost anything, but electric lights are characterized by significant expenses. It requires electricity whose generation requires a lot of process, during production and transmission. Due to high cost needed for production of electricity and to compensate the transmission loss of electricity, the utilization of electricity, costs $\theta$ a huge percentage in the share of revenue, made by a shopping mall and complex. Saving light energy in the parking space itself, saves a lot of amount in the electricity bill. 
Journal of Electronics and Informatics (2020)

Vol.02/ No. 01

Pages: $18-29$

http://www.irojournals.com/iroei/

DOI: https://doi.org/10.36548/jei.2020.1.003

The following list shows the existing available methods in saving light energy.

- Switching off the lighting system when it is not needed.

- By replacing the lamps with lesser power.

- Minimizing the lighting lumens.

- Partially switching of certain lamps.

- Partially minimizing the lighting lumens.

All these existing methods are in need of manual support and verification. Even if we automate such methods using a microcontroller, these existing methods will have certain limitations. These methods are not suitable of each and every places. The comfort level of the utilizer will also become a questionable one, when implementing such methods. Also, these methods may give a way for happening of crime instances in such parking places. In order to avoid such drawbacks, Compact Fluorescent Lamp (CFL) and Light Emitting Diodes (LED) were introduced to reduce the power consumption by up to $75 \%$. Table 1 explicates the required lamp power in watts for same lumens in comparison with the various types of lamps.

\begin{tabular}{|c|c|c|c|}
\hline Light Output & Incandescent & CFL & LED \\
\hline Lumens & \multicolumn{3}{|c|}{ Power in watts } \\
\hline 450 & 40 & 8 & 4 \\
\hline 500 & 60 & 13 & 6 \\
\hline 1200 & 75 & 18 & 9 \\
\hline
\end{tabular}

ISSN: 2582-3825 (online) 
Journal of Electronics and Informatics (2020)

Vol.02/ No. 01

Pages: $18-29$

http://www.irojournals.com/iroei/

DOI: https://doi.org/10.36548/jei.2020.1.003

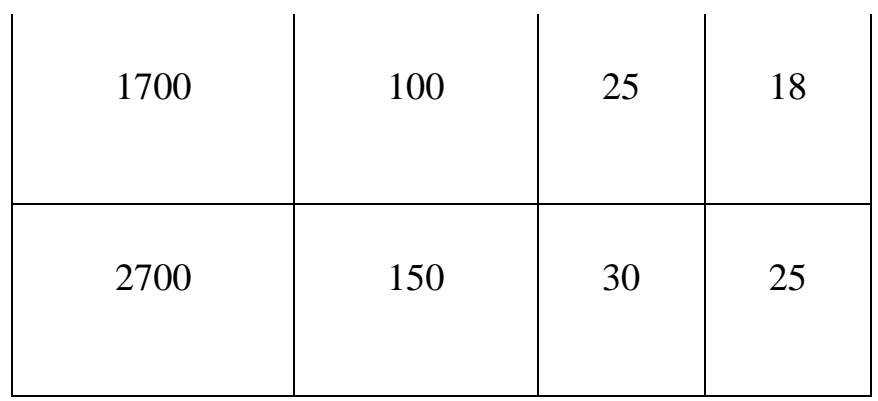

Table 1. Comparison of lamps power with lumens.

An efficient energy saving system with combination of LED and CFL lamp reduces the power consumption from $75 \%$ to $90 \%$ in real time operations. An intelligent system based on wireless sensor network for saving the light energy on road side lights [1] was developed to save the energy consumption. The light energy is saved here, by fixing the nodes evenly in certain distances. These nodes consists of vehicle movement detection sensor for identifying the vehicle movement, wireless transmission protocol for sending the information and a lighting control hardware for switching ON and OFF the lamps. These nodes were also used for finding out the traffic conditions, and weather conditions. An intermediate node [2] between the transmission and receiver node for carrying the valuable information measured by the sensors efficiently is proposed in the literature. An energy saving street light control system [3] was proposed, to minimize the energy consumption. The system is managed with outputs received from temperature and daylight sensors, installed near to each lamp units. The interface module connected between the sensor unit and power unit controls the lighting system, with respect to the change in atmosphere. An IoT based greenhouse environment system [4], was designed for sensing the needs of the plants with respect to the changes in climate conditions. The sensor data are transmitted through a wi-fi module by reducing transmission cost.

An energy-saving system [5] in highway tunnel lighting process system consists of multiple sensors for reading the vehicle detection and vehicle speed along with the required lighting demand on particular place, to illuminate the lamps. The lighting demand is calculated with respect to available environmental luminance, which was captured by an image taken from road surveillance camera. An incremental proportional integral derivative scheme is implemented in this unit for matching the need of tunnel lighting system. An efficient routing protocol [6] was insisted to avoid node transmission loss between vehicle networks on their move. Energy-saving control method [7] for building, by considering the user satisfaction, identifies the presence of number of users in a room and their activity to modify the light power requirement. The designed system is verified in a real time operation and it reduced the supply utilization maximum to 43\%. An optimized hybridization technique [8] was framed for transmitting the data sensed by the sensor to faraway destination, to reduce transmission energy consumption. The framed algorithm is designed to forward the carried information in heavy traffic nodes.

ISSN: 2582-3825 (online) 
Journal of Electronics and Informatics (2020)

Vol.02/ No. 01

Pages: $18-29$

http://www.irojournals.com/iroei/

DOI: https://doi.org/10.36548/jei.2020.1.003

A smart building lighting control system [9] was structured by identifying the position of users in a building. To identify the user's position, the systems have multiple wi-fi modem on the building. The identified location is transmitted to the server, and by reading information of occupancy, the application installed for controlling the brightness will change the power requirement to the lamp control unit. A green cloud computing technique [10] was introduced to save energy consumption in data transmission through wired lines. The impact of environment impact in transmission is reduced in this cloud transmission system. A light dimming energy saving system [11] was framed in a building by identifying the user's occupancy count. To count out the number of occupancy in a room, the framed system proposes a self-error correlation occupancy counting algorithm. From the counted number of occupancy, the value is transmitted to the cyber physical system which was already placed in that building for safety purpose. Then, the adaptive dimmable lighting energy management scheme controls the lumens requirement in a building. A secure and smart IoT artificial intelligence system [12] was introduced to monitor the hospital environment safely, without losing the collected information during remote transmission.

An advanced lighting system [13] was arranged in public areas to save energy with user satisfaction. The system presents a study in terms of measuring the poles height and distance, along with kind of lamps fixed. The system also carries a survey, for identifying the user preference, in terms of amount of light to be illuminated in such public areas, while they are walking and driving. With respect to the data collected through monitoring and surveying the system, they framed the proposed system with the required lumens, to illuminate in the public area. For identifying the people's movement, the system is fixed with Passive Infra-Red (PIR) sensor. The user satisfaction is achieved to $81 \%$ in the test area and the energy consumption is reduced up to $70 \%$. A cloud based IoT system [14] for energy saving process in home devices is also presented in the literature. All the devices connected through the cloud systems are controlled by the processor with the respective algorithm designed for saving the energy. Literature also presents a lighting system [15] for a work place in a combination of natural light and artificial light source. A Fresnel lens solar tracker is fixed for identifying the natural light source position and amount of light received from it. The feedback from the solar tracker is forwarded to the sensor feedback system to illuminate the artificial lighting source system to the workplace. The performance of the sensor node transmission can be improved by a secured self-organizing algorithm [16] to avoid the black hole and wormhole attack.

A highway lighting system [17] was proposed as control unit for providing a cost effective lighting system, by maintaining the driving comfort. The system is implemented with IoT based transmission, for detecting the traffic information of the highway and providing enough light source to the roads. For improving the performance of such IoT based systems, data mining algorithms [18] can be added. A hybrid lighting system [19] in combination of natural light with LED lights, to provide enough light source while driving in a tunnel, has been proposed in the literature. Tunnel roads always have slightly better natural light on its entry and exit point. So, it is carried out into account in this work, for calculating remaining amount of light requirement in the entry and exist point, during needy times. An enhanced edge model [20] is an efficient technology for transmitting big data for IoT based applications. An energy efficient lighting

ISSN: 2582-3825 (online)

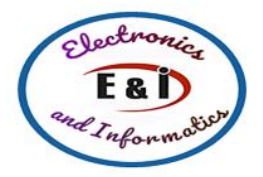


Journal of Electronics and Informatics (2020)

Vol.02/ No. 01

Pages: $18-29$

http://www.irojournals.com/iroei/

DOI: https://doi.org/10.36548/jei.2020.1.003

system [21] was arranged for street roads through a wi-fi module. The wi-fi module reads the status of the connected IR sensor for vehicle movement detection and LDR sensor for natural light status. With respect to the values received from the sensors, the programmed mobile app will send the signal to switch ON/OFF/dimming the LED lamps over the streets. The wireless transmission through wi-fi module between the sensor and the processor system can be affected by the third party nodes, for hacking the transmission data. This can be happen in any wireless transmission, especially, in the public nodes transmission in the public areas. Hence, attack-resilient malicious node detection scheme [22] can be added for security reason.

\section{Proposed Method}

The proposed energy saving system is an independent control system, developed for reducing the energy consumption in large parking places like shopping malls, apartments, and certain other public and private parking spots. The motive of the proposed scheme is provide Enough light source, while driving a vehicle for parking and walking OUT/IN through the vehicle. The system is also developed with a change of mode in the lighting system to give surveillance to the parking area. The change of mode is connected as a manual operation system to achieve a physical verification of the whole system, during its operation. Figure 1 shows the blocks involved in designing the proposed automatic energy saving system.

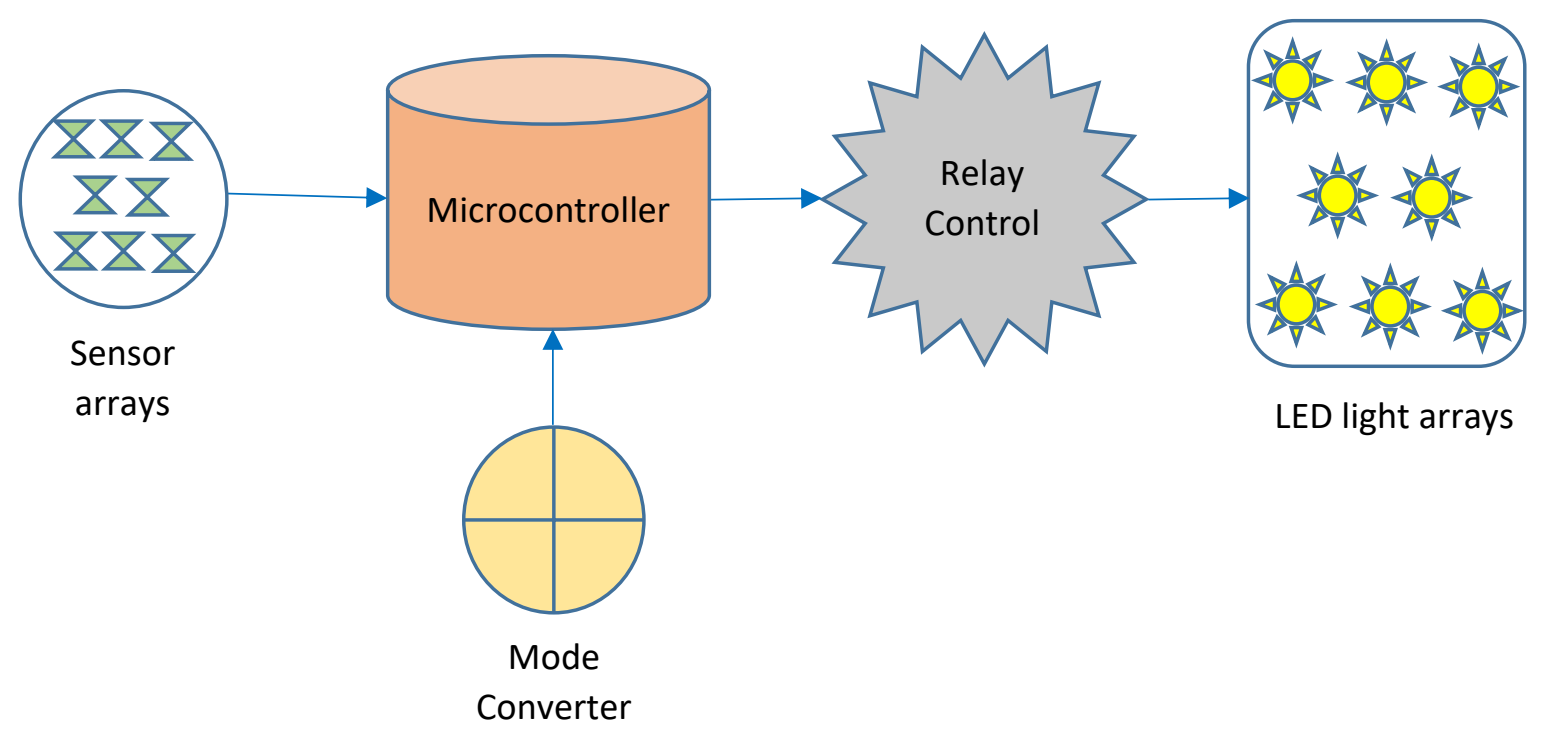

Figure 1. Block diagram of the proposed energy saving system

The proposed system consists of a microcontroller which acts like a brain in the energy saving system. The microcontroller is connected with a group of sensors, to read the real time status of parking spot. Similarly,

ISSN: 2582-3825 (online) 
Journal of Electronics and Informatics (2020)

Vol.02/ No. 01

Pages: $18-29$

http://www.irojournals.com/iroei/

DOI: https://doi.org/10.36548/jei.2020.1.003

the LED lights are connected to the microcontroller through a relay control unit, for ON/OFF and dimming operation. To convert the mode of operation of the proposed energy saving system, a digital switch is connected to the microcontroller, which can be operated manually. Each car block in the parking area is connected with two different wattage lamps and a PIR (Passive InfraRed) sensor. Lamp 1 is a lamp with sufficient lumens to illuminate the parking area and lamp 2 with lesser wattage to just look up the area for safety purpose. Both the lamp 1 and lamp 2 is connected with the relay control for its independent operation. The relay control part unit of each block is connected with the microcontroller. With respect to the number of input output pins for connecting the sensors and relay units, the number of microcontroller needed for the parking area can be changed. A simple microcontroller with 14 digital input and output pin can be used for 4 parking spots. All these four parking spots can have a single mode switch for its operation. The mode switches can be reduced to one number, for ' $n$ ' number of microcontrollers, just by connecting all those switches in a parallel connection manner.

\section{MODE 1 Operation:}

In the mode 1 operation, the connected system will always illuminate the parking spot with lesser light lumens with lamp 2 just for a person to identify the availability of the parking area visually. This mode is needed during the working time or movement time in the parking spot. After parking the vehicle, the PIR sensor will detect the human movement around the car, when they are coming out of the vehicle, and, it sends the digital signal to the microcontroller to switch on the sufficient lumens lamp 1. The operation of lamp 2 will be cut off at this point, to save the energy. After a human moves away from the parking spot, the PIR sensor sends the signal back to the microcontroller, to switch-off the lamp 1 and switch 'ON' the lamp 2 for saving the energy. The lamp 1 illumination will be helpful, when getting in and out of the vehicle. The operation process is given in figure 2 for easy understanding.

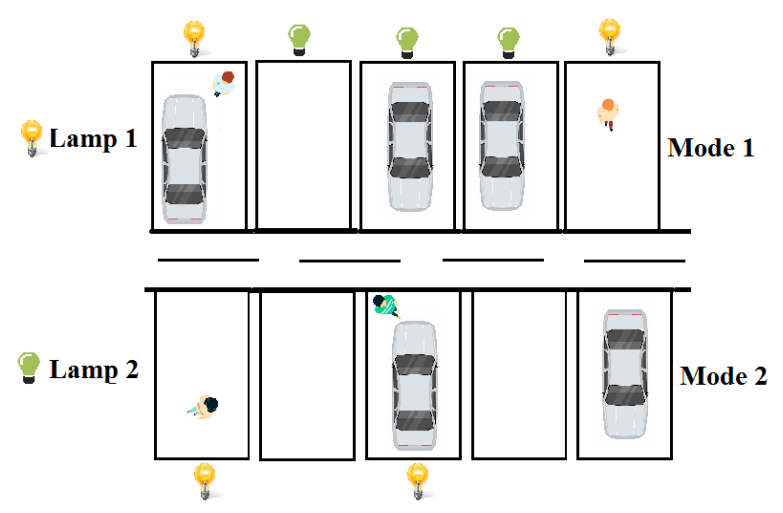

Figure 2. Operation process of the proposed energy saving system

ISSN: 2582-3825 (online) 
Journal of Electronics and Informatics (2020)

Vol.02/ No. 01

Pages: $18-29$

http://www.irojournals.com/iroei/

DOI: https://doi.org/10.36548/jei.2020.1.003

\section{MODE 2 Operation:}

The mode 2 operation is a super power saving mode, where both lamp 1 and lamp 2 will be in 'OFF' mode, for saving the power. The lamp 1 will be illuminated when there is a human movement in the parking area. This mode can be availed under mid-night operation in the parking area. As the system switches 'ON' the lamp 1 with good lumens to power up the parking spot, it will avoid the criminal things to happen near the parking spot. The figure 3 explores the working operation of the proposed system with the help of a flowchart.

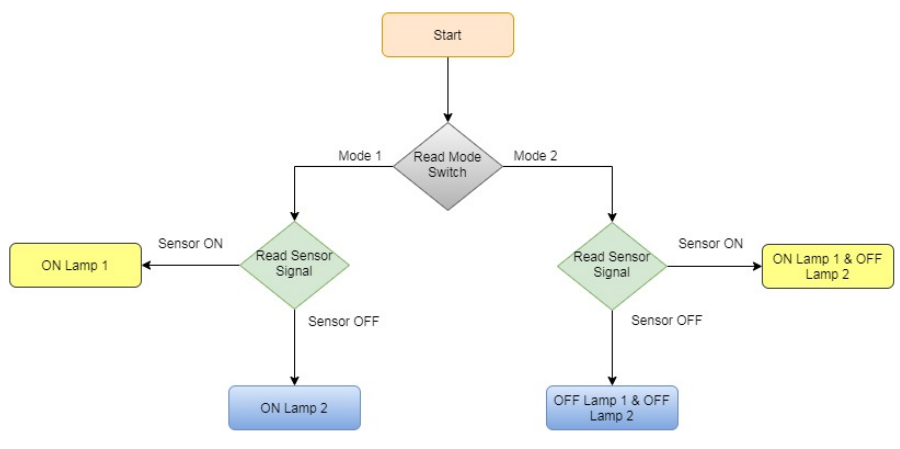

Figure 3. Flow chart of the proposed light energy saving system.

\section{Results and Discussion:}

Table 2 explores the amount of energy consumed in a parking area of 10 vehicles, by 5 to 5 opposite to each other as shown in figure 3, during general operation condition. Similarly, table 3 exhibits the energy consumed by the proposed energy saving system for state 1 operation and table 4 is calculated for state 2 operation. The state 1 and state 2 operation is calculated by assuming the lamp 1 and lamp 2 'ON' state condition. In all the measurements, mode 1 operation is carried out from $6 \mathrm{pm}$ to $12 \mathrm{am}$ and mode 2 operation is taken in to account from 12am to 6am. The general operation is calculated for the same timings. The LED lamps are used for reading purpose and the wattage of lamp 1 and lamp 2 is 9watts and 4watts respectively.

General Operation

ISSN: 2582-3825 (online) 
Journal of Electronics and Informatics (2020)

Vol.02/ No. 01

Pages: $18-29$

http://www.irojournals.com/iroei/

DOI: https://doi.org/10.36548/jei.2020.1.003

\begin{tabular}{|l|c|c|}
\cline { 2 - 3 } Time of Operation & $6 \mathrm{pm}-12 \mathrm{am}$ & $12 \mathrm{am}-6 \mathrm{am}$ \\
\hline Lamps & 10 & 4 \\
\hline Power & $9 \mathrm{~W}$ & $9 \mathrm{~W}$ \\
\hline Total Power & $90 \mathrm{~W}$ & $36 \mathrm{~W}$ \\
\hline Power Consumed & $540 \mathrm{~W}$ & $216 \mathrm{~W}$ \\
\hline Total Power Consumed & \multicolumn{2}{|c|}{$756 \mathrm{Watts} /$ day } \\
\hline
\end{tabular}

Table 2. Energy consumed in general operation

\begin{tabular}{|c|c|c|c|}
\hline \multirow[b]{2}{*}{ State 1 Operation } & \multicolumn{3}{|c|}{ Proposed Method Operation } \\
\hline & $\begin{array}{c}\text { Proposed Mode } 1 \\
\text { Operation with Lamp } 1 \\
\text { 'ON' state } \\
\text { (Lamp } 1 \text { 'ON' state is } \\
\text { assumed as 10minutes } \\
\text { working in 30minutes } \\
\text { operation) }\end{array}$ & $\begin{array}{c}\text { Proposed Mode } 1 \text { Operation } \\
\text { with Lamp } 2 \text { 'ON' state } \\
\text { (Lamp } 2 \text { 'ON' state is } \\
\text { assumed as 20minutes } \\
\text { working in 30minutes } \\
\text { operation) }\end{array}$ & $\begin{array}{c}\text { Proposed Mode } 2 \\
\text { Operation with Lamp } 1 \\
\text { 'ON' state } \\
\text { (Lamp 1 'ON' state is } \\
\text { assumed as 5minutes } \\
\text { working in 30minutes } \\
\text { operation) }\end{array}$ \\
\hline $\begin{array}{c}\text { Time/Mode of } \\
\text { Operation }\end{array}$ & $6 \mathrm{pm}-12$ am/Mode 1 & $6 \mathrm{pm}-12$ am/Mode 1 & $12 \mathrm{am}-6 \mathrm{am} /$ Mode 2 \\
\hline Lamps & 10 & 10 & 10 \\
\hline Power & $9 \mathrm{~W}$ & $4 \mathrm{~W}$ & $9 \mathrm{~W}$ \\
\hline Total Power & $90 \mathrm{~W}$ & $40 \mathrm{~W}$ & $90 \mathrm{~W}$ \\
\hline Power Consumed & $180 \mathrm{~W}$ & $160 \mathrm{~W}$ & \\
\hline $\begin{array}{c}\text { Power Consumed in } \\
\text { mode operation }\end{array}$ & \multicolumn{2}{|c|}{$340 \mathrm{~W}$} & $90 \mathrm{~W}$ \\
\hline $\begin{array}{c}\text { Total Power } \\
\text { Consumed }\end{array}$ & \multicolumn{3}{|c|}{430 Watts/day } \\
\hline
\end{tabular}

Table 3. Energy consumed in the proposed energy saving operation at state 1 .

\begin{tabular}{|c|c|c|c|}
\hline \multirow{5}{*}{ State 2 Operation } & \multicolumn{3}{|c|}{ Proposed Method Operation } \\
\cline { 2 - 4 } & $\begin{array}{c}\text { Proposed Mode 1 } \\
\text { Operation with Lamp 1 } \\
\text { 'ON' state } \\
\text { (Lamp 1 'ON' state is } \\
\text { assumed as 5minutes } \\
\text { working in 30minutes } \\
\text { operation) }\end{array}$ & $\begin{array}{c}\text { Proposed Mode 1 Operation } \\
\text { with Lamp 2 'ON' state } \\
\text { (Lamp 2 'ON' state is } \\
\text { assumed as 25minutes } \\
\text { working in 30minutes } \\
\text { operation) }\end{array}$ & $\begin{array}{c}\text { Proposed Mode 2 } \\
\text { Operation with Lamp 1 } \\
\text { 'ON' state } \\
\text { (Lamp 1 'ON' state is } \\
\text { assumed as 5minutes } \\
\text { working in 30minutes } \\
\text { operation) }\end{array}$ \\
\hline $\begin{array}{c}\text { Time/Mode of } \\
\text { Operation }\end{array}$ & $6 \mathrm{pm}-12$ am/Mode 1 & $6 \mathrm{pm}-12$ am/Mode 1 & 12am - 6am/Mode 2 \\
\hline
\end{tabular}

ISSN: 2582-3825 (online) 
Journal of Electronics and Informatics (2020)

Vol.02/ No. 01

Pages: $18-29$

http://www.irojournals.com/iroei/

DOI: https://doi.org/10.36548/jei.2020.1.003

\begin{tabular}{|c|c|c|c|}
\cline { 2 - 4 } Lamps & 10 & 10 & 10 \\
\hline Power & $9 \mathrm{~W}$ & $4 \mathrm{~W}$ & $9 \mathrm{~W}$ \\
\hline Total Power & $90 \mathrm{~W}$ & $40 \mathrm{~W}$ & $90 \mathrm{~W}$ \\
\hline Power Consumed & $90 \mathrm{~W}$ & $200 \mathrm{~W}$ & $90 \mathrm{~W}$ \\
\hline $\begin{array}{c}\text { Power Consumed in } \\
\text { mode operation }\end{array}$ & \multicolumn{2}{|c}{$290 \mathrm{~W}$} \\
\hline $\begin{array}{c}\text { Total Power } \\
\text { Consumed }\end{array}$ & $380 \mathrm{Watts} /$ day \\
\hline
\end{tabular}

Table 4. Energy consumed in the proposed energy saving operation at state 2.

Figure 4 specifies the graphical comparison on the performance of the proposed energy saving system during mode 1, mode 2 operation with the general operation system. The state 1 and state 2 operations of the proposed system is showing better performance than the general operation. Figure 5 indicates the difference on consumed energy between the state 1 and state 2 operation of the proposed energy saving system. It shows a change in performance between state 1 and state 2 operation. The ' $O N$ ' condition time of lamp 1 is reduced in state 2, so that, the performance of state 2 is gradually improved. Figure 6 directs the day-wise performance comparison of the proposed system with general operation. The performance of the state 1 and state 2 operation is better than the general operation system and the energy consumption of the proposed system in state 1 is saved to $43.13 \%$ and state 2 operation is saved to $49.74 \%$. So, the proposed system saves energy in an average range of $46.43 \%$.

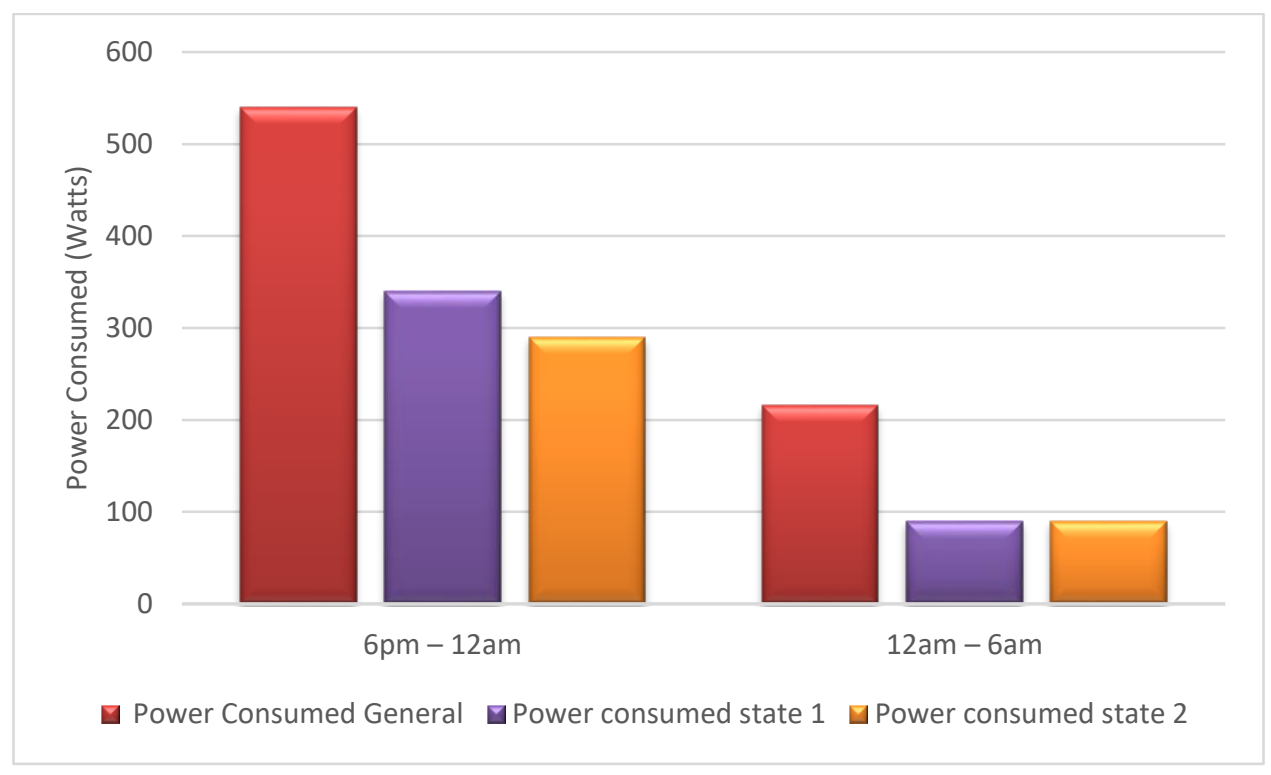

Figure 4: Performance comparison of the proposed system mode 1, mode 2 with general operation.

ISSN: 2582-3825 (online) 
Journal of Electronics and Informatics (2020)

Vol.02/ No. 01

Pages: $18-29$

http://www.irojournals.com/iroei/

DOI: https://doi.org/10.36548/jei.2020.1.003

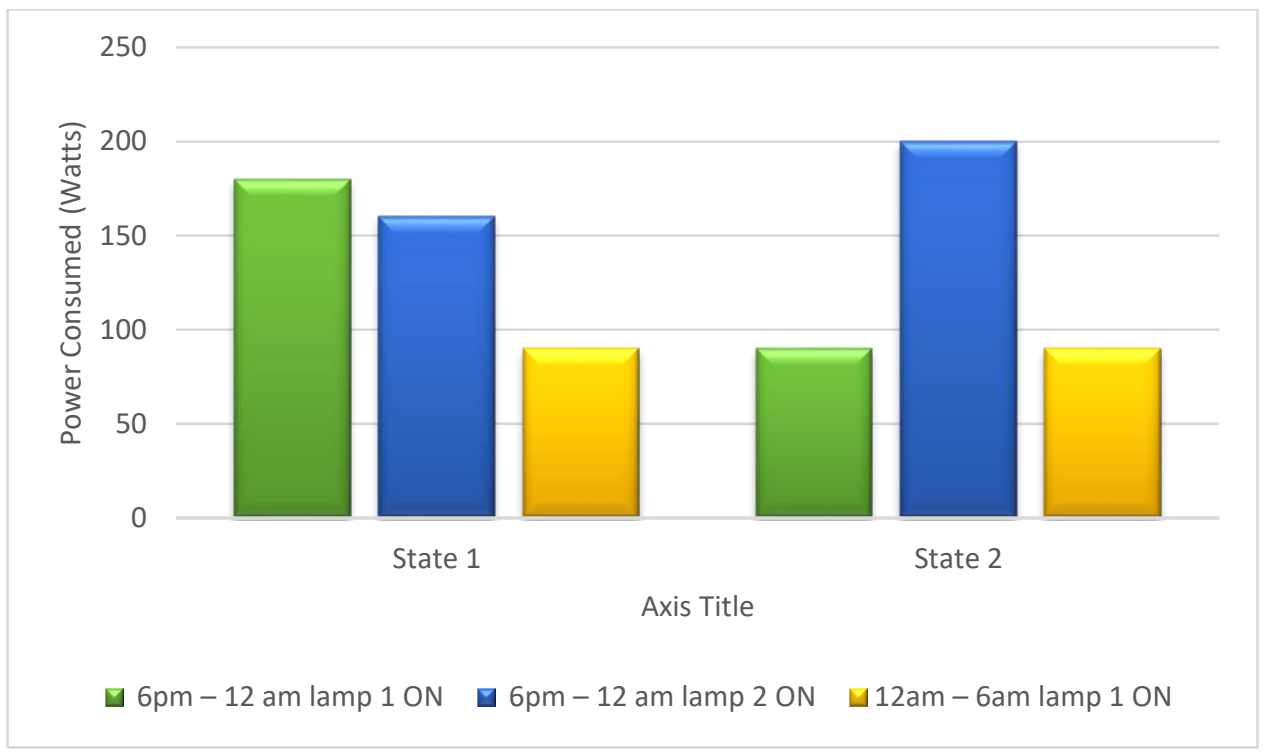

Figure 5: Performance comparison of the proposed system state 1 and state 2 operation.

\section{Total energy consumed/day in Watts}

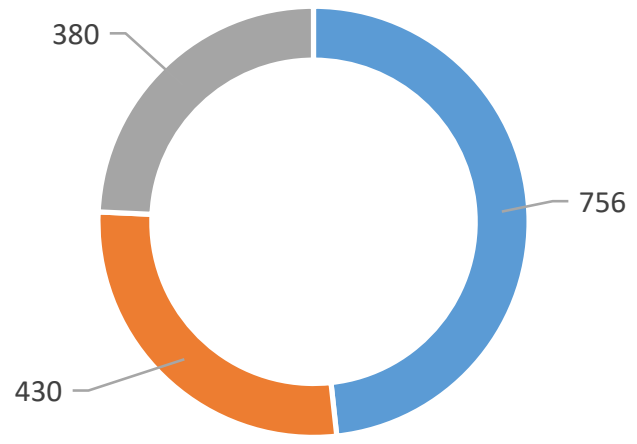

- Genral operation = Proposed stae 1 operation n Proposed stae 2 operation

Figure 6: Performance comparison of the proposed system with general operation per day.

\section{Conclusion}

The proposed automatic energy saving system is analyzed for the recent LED lamps. The LED lamps are $80 \%$ to $90 \%$ efficient than the existing incandescent lamps and the proposed system makes it more efficient than the incandescent lamp system. The energy consumption of the present LED lighting system is improved with the proposed energy saving system up to $46.43 \%$. The proposed method is designed to avoid criminal offense with cost efficiency in the public car parking area. The efficiency of the proposed system 
Journal of Electronics and Informatics (2020)

Vol.02/ No. 01

Pages: $18-29$

http://www.irojournals.com/iroei/

DOI: https://doi.org/10.36548/jei.2020.1.003

can be improved by implementing a wireless sensor for measuring the atmospheric light remotely, to monitor and illuminate the enough lumens in the parking area.

\section{References}

[1] Todorović, Branislav M., and Dragan Samardžija. "Road lighting energy-saving system based on wireless sensor network." Energy Efficiency 10, no. 1 (2017): 239-247.

[2] Smys, S., and G. Josemin Bala. "Efficient self-organized backbone formation in mobile ad hoc networks (MANETs)." Computers \& Electrical Engineering 38, no. 3 (2012): 522-532.

[3] Ożadowicz, Andrzej, and Jakub Grela. "Energy saving in the street lighting control systemA new approach based on the EN-15232 standard." Energy Efficiency 10, no. 3 (2017): 563576.

[4] Raj, Jennifer S., and J. Vijitha Ananthi. "Automation using IoT in greenhouse environment." Journal of Information Technology 1, no. 01 (2019): 38-47.

[5] Qin, Li, Lili Dong, Wenhai Xu, Lidong Zhang, Qiubo Yan, and Xiaodong Chen. "A "vehicle in, light brightens; vehicle out, light darkens" energy-saving control system of highway tunnel lighting." Tunnelling and Underground Space Technology 66 (2017): 147-156.

[6] Sivaganesan, D. "Efficient routing protocol with collision avoidance in vehicular networks." Journal of Ubiquitous Computing and Communication Technologies (UCCT) 1, no. 02 (2019): 76-86.

[7] Byun, Jinsung, and Taehwan Shin. "Design and implementation of an energy-saving lighting control system considering user satisfaction." IEEE Transactions on Consumer Electronics 64, no. 1 (2018): 61-68.

[8] Sathesh, A. (2019). Optimized multi-objective routing for wireless communication with load balancing. Journal of trends in Computer Science and Smart technology (TCSST), 1(02), 106120.

[9] Zou, Han, Yuxun Zhou, Hao Jiang, Szu-Cheng Chien, Lihua Xie, and Costas J. Spanos. "WinLight: A WiFi-based occupancy-driven lighting control system for smart building." Energy and Buildings 158 (2018): 924-938.

[10] Bindhu, V. "Green cloud computing solution for operational cost efficiency and environmental impact reduction." Journal of Ismac 1, NO. 02 (2019): 120-128.

[11] Lee, Changmin, Duckhee Lee, and Jaiyong Lee. "Occupancy-based adaptive dimmable lighting energy management scheme combined with cyber physical system." In 2018 International Conference on Information Networking (ICOIN), pp. 605-610. IEEE, 2018.

[12] Valanarasu, Mr R. "Smart and secure iot and ai integration framework for hospital environment." Journal of ISMAC 1, no. 03 (2019): 172-179.

[13] Beccali, M., M. Bonomolo, V. Lo Brano, G. Ciulla, V. Di Dio, F. Massaro, and S. Favuzza. "Energy saving and user satisfaction for a new advanced public lighting system." Energy Conversion and Management 195 (2019): 943-957.

ISSN: 2582-3825 (online) 
Journal of Electronics and Informatics (2020)

Vol.02/ No. 01

Pages: $18-29$

http://www.irojournals.com/iroei/

DOI: https://doi.org/10.36548/jei.2020.1.003

[14] Duraipandian, M., and R. Vinothkanna. "Cloud based Internet of Things for smart connected objects." J. ISMAC 1, no. 02 (2019): 111-119.

[15] Han, Hyun Joo, Muhammad Uzair Mehmood, Rahate Ahmed, Yeongmin Kim, Spencer Dutton, Sang Hoon Lim, and Wongee Chun. "An advanced lighting system combining solar and an artificial light source for constant illumination and energy saving in buildings." Energy and Buildings 203 (2019): 109404.

[16] Jyothirmai, Pondi, Jennifer S. Raj, and S. Smys. "Secured self organizing network architecture in wireless personal networks." Wireless Personal Communications 96, no. 4 (2017): 56035620.

[17] Rahman, Md Arafatur, A. Taufiq Asyhari, Mohammad S. Obaidat, Ibnu Febry Kurniawan, Marufa Yeasmin Mukta, and P. Vijayakumar. "IoT-Enabled Light Intensity-Controlled Seamless Highway Lighting System." IEEE Systems Journal (2020).

[18] Joseph, S. Iwin Thanakumar, and Iwin Thanakumar. "Survey of data mining algorithm's for intelligent computing system." Journal of trends in Computer Science and Smart technology (TCSST) 1, no. 01 (2019): 14-24.

[19] Chen, Hong-Yi, Allen Jong-Woei Whang, Yi-Yung Chen, and Chun-Han Chou. "The hybrid lighting system with natural light and LED for tunnel lighting." Optik 203 (2020): 163958.

[20] Pandian, A. Pasumpon. "Enhanced edge model for big data in the internet of things based applications." Journal of trends in Computer Science and Smart technology (TCSST) 1, no. 01 (2019): 63-73.

[21] Singh, Vibhanshu, and Sangeeta Mittal. "Internet of Streetlights for Energy Efficient Smart Lighting System." In Smart Systems and IoT: Innovations in Computing, pp. 609-616. Springer, Singapore, 2020.

[22] Anguraj, Dinesh Kumar, and S. Smys. "Trust-based intrusion detection and clustering approach for wireless body area networks." Wireless Personal Communications 104, no. 1 (2019): 1-20.

ISSN: 2582-3825 (online) 